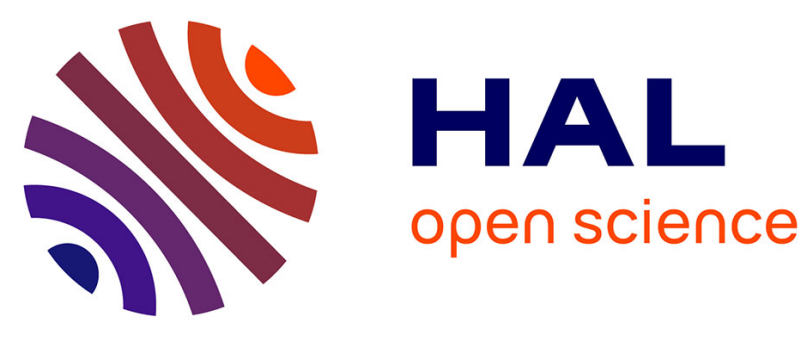

\title{
Design and thermal assessment of a micro electromagnetic actuator
}

Muneeb Ullah Khan, Amaury Charvet, Jérémy Terrien, Frédéric Lamarque, Christine Prelle

\section{- To cite this version:}

Muneeb Ullah Khan, Amaury Charvet, Jérémy Terrien, Frédéric Lamarque, Christine Prelle. Design and thermal assessment of a micro electromagnetic actuator. 2016 11th France-Japan \& 9th EuropeAsia Congress on Mechatronics (MECATRONICS) /17th Internationall Conference on Research and Education in Mechatronics (REM), Jun 2016, Compiègne, France. pp.260-265. hal-02120851

\section{HAL Id: hal-02120851 \\ https://hal.utc.fr/hal-02120851}

Submitted on 6 May 2019

HAL is a multi-disciplinary open access archive for the deposit and dissemination of scientific research documents, whether they are published or not. The documents may come from teaching and research institutions in France or abroad, or from public or private research centers.
L'archive ouverte pluridisciplinaire HAL, est destinée au dépôt et à la diffusion de documents scientifiques de niveau recherche, publiés ou non, émanant des établissements d'enseignement et de recherche français ou étrangers, des laboratoires publics ou privés. 


\title{
Design and thermal assessment of a micro electromagnetic actuator
}

\author{
Muneeb Ullah Khan, Amaury Charvet, Jérémy Terrien, Frédéric Lamarque and Christine Prelle \\ Sorbonne universités, Université de technologie de Compiègne (UTC) \\ CNRS, UMR 7337 Roberval, Centre de recherche Royallieu \\ CS 60319-60203 Compiègne cedex, France \\ muneeb-ullah.khan@utc.fr, amaury.charvet@etu.utc.fr, jeremy.terrien@utc.fr, frederic.lamarque@utc.fr, christine.prelle@utc.fr
}

\begin{abstract}
In this paper, an experimental study to investigate maximum drive current handling capability of a compact electromagnetic actuator is presented. The actuator design consists of a mobile part and a fixed part. The mobile part assembles two pairs of six permanent magnets into a small cross structure. The fixed part integrates two planar electric drive coils. These coils are isolated from each other and are fabricated into top and second layer of a four layer printed circuit board. In addition, to reduce the overall temperature of the fixed part, a thermal pad has been integrated. During experimentation, the actuator was injected with different amplitude of sinusoidal currents, to drive the mobile micro pallet onto the fixed part. A thermal sensor is used to measure the surface temperature rise due to joule heating. From experimental results, it has been concluded that the proposed actuator design can handle upto $0.8 \mathrm{~A}$ of sinusoidal current with a maximum rise in surface temperature of $48^{\circ} \mathrm{C}$ in 100 cycles test of $8 \mathrm{~mm}$ along both $x$ - and $y$-axis. The maximum cooling time was found to be 450 seconds.
\end{abstract}

Keywords-electromagnetic actuator, permanent magnets, temperature measurement, joule heating, finite element analysis.

\section{INTRODUCTION}

In recent years, electromagnetic actuation technology has been widely adapted in micro applications. High speed and dynamics, fast response time are some of the promising features of this technology [1], [2]. Their magnetic levitation characteristics are often adapted to eliminate friction and adherence effects that appears due to the contact between the mobile part and fixed part of these actuators [3], [4]. These characteristics makes electromagnetic actuators suitable for high precision and positioning tasks in micro applications such as chip manufacturing, biomedicine, surface characterisation, etc, [5]-[7].

Although, electromagnetic actuators are being successfully applied into numerous domains as described above, the growing trend of miniaturization have made modern electromagnetic actuator designs more challenging. For example, to accomplish smaller dimensions for these actuators, the overall dimensions of their main components such as Permanent Magnets (PMs), drive coils, and mechanical holding structure, need to be minimized [8]. Thanks to advancements in the microfabrication technology, nowadays, coils and mechanical structure with micrometer level dimensions and shapes can easily be achieved. Furthermore, the advancement in material science technology have encouraged researcher to develop small PMs with modern magnetic material such as Samarium cobalt, Neodymium Iron Boron, etc., to be easily adapted to modern electromagnetic actuator designs [9], [10].

In micro electromagnetic actuator designs, two approaches are often utilized. First, a moving coils and fixed PMs approach [11] and second, fixed coils and moving PMs technique [12]. In the first approach, the current carrying conductors are placed on the rotor side and a concentrated magnetic field is formed using multiple PMs. This approach often leads to a complex design demanding continuous power connections at the rotor end of the actuator. On the contrary, the second design approach is often preferred to achieve wire free design of the mobile part that integrates PMs [13]. Although, both design approaches have their merits but one of the common problem associated with electromagnetic actuators is joule heating. In down scaled versions of these actuators, the need of injecting high currents to generate large electromagnetic forces often results in deterioration of PMs or drive coils. One of the solution apart from the lowering the magnitude of the injected current, is to introduce cooling structures (e.g., thermal fins, etc.). In addition to these structures, a forced cooling can also be performed to remove the generated heat from the coils using micro fans. However, the introduction of these components can increase complexity in the overall design as well as increase power consumption of the micro electromagnetic actuators. Moreover, these elements can increase overall cost and dimensions of the actuators.

In planar electromagnetic micro actuators based on fixed coils and moving magnets approach, the overall design of the device can be optimized to evacuate the generated joule heat by means cooling structures such as thermal pads in the fixed part. This approach disperses the generated heat due to the large surface area of thermal pads. As a result, higher currents can be injected while significantly reducing the temperature rise without need of forced cooling techniques. Moreover, a compact and more economical actuator design can be assured.

In this paper, a novel planar electromagnetic actuator design is proposed. The drive coils of the actuator have been designed and fabricated in a four layer Printed Circuit Board (PCB) to achieve compact dimensions. In addition, to improve the current handling capability of the drive coils, a thermal pad layer has been developed to disperse the generated joule heat. Analysis and experiments have been conducted to study the maximum surface temperature rise on the fixed part of the actuator (see section III). At the end, the maximum current handling capability of the actuator design without increasing the temperature that helps in deteriorating the magnetization 
of the PMs is presented in section V. At the end conclusion is given and perspectives are discussed in section VI.

\section{Design layout AND ACtUATION PRINCIPLE OF THE ELECTROMAGNETIC ACTUATOR}

The design of the electromagnetic actuator consists of a mobile part (called micro pallet) and a fixed part as shown in the Fig.1. The mobile part integrates a pair of six permanent magnets along $x$ - and $y$-axis. The PMs have been arranged in North-South (NS) configuration to facilitate self-assembly and achieve symmetrical magnetic field [13]. The mechanical cross structure to assemble the PMs of the micro pallet has been laser cut in a $0.5 \mathrm{~mm}$ thick Plexiglas acrylic sheet. In addition, to provide a smooth insulation medium between the micro pallet and current carrying conductors, a thick glass layer has been also cut using laser cutting technology. The geometrical parameters are provided in table I. The specific shape of the cross structure has been adapted to minimize overall weight of the micro pallet.

The fixed part consists of two Planar Electric Drive Coils (PEDCs). These PEDCs have been commercially fabricated using a four layer PCB technology as depicted in Fig.1. The top layer includes a PEDC to drive the micro pallet along $y$ axis. The second layer consists of a PEDC that is orthogonally oriented in $x y$-plane with respect to top layer PEDC. The second layer PEDC are used to drive the micro pallet along $x$-axis. If PEDCs of both layers are injected with sinusoidal currents, a motion in $x y$-plane can be achieved. In addition, to the above mentioned layer, the fixed part integrates a thermal pad in the third layer to evacuate the joule heat. This thermal pad is connected to the bottom layer through thermal vias. Furthermore, the bottom side of the fixed part is used to inject the currents using power source wires through a PCB connector that is connected to the PEDCs in top and second layer of the fixed part of the actuator.

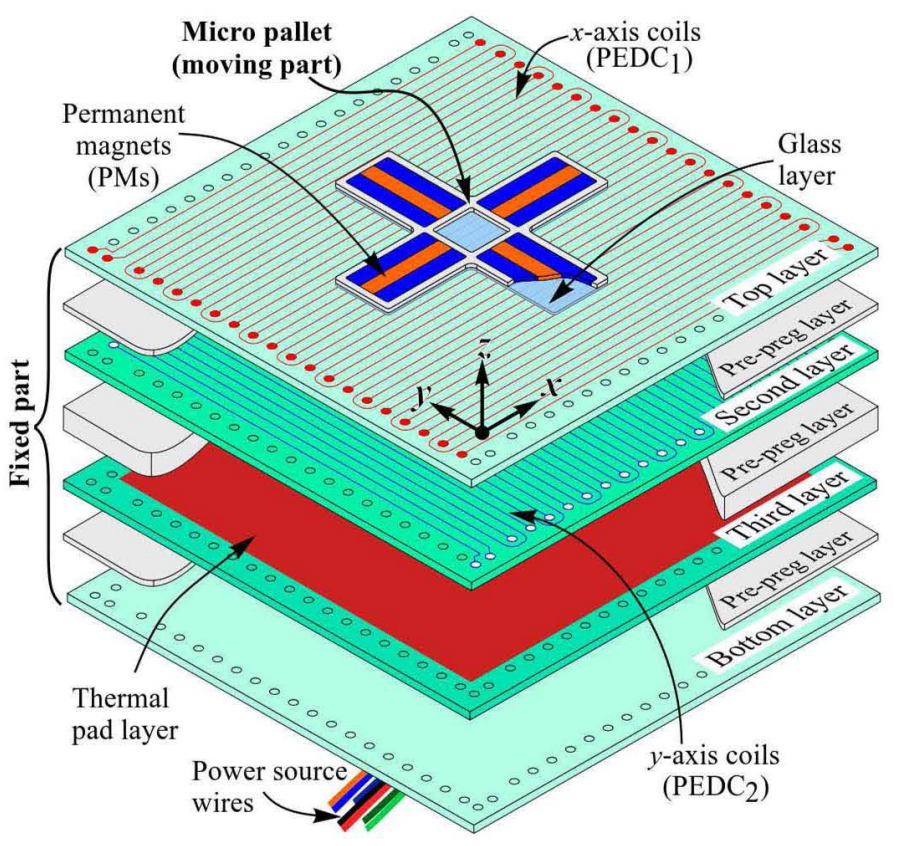

Fig. 1. 3D isometric view of the micro actuator design model.
TABLE I. THE PHYSICAL CHARACTERISTICS OF THE ACTUATOR

\begin{tabular}{lc}
\hline Parameter & Value \\
\hline Permanent magnet dimensions & $1 \mathrm{~mm} \times 6 \mathrm{~mm} \times 0.5 \mathrm{~mm}$ \\
Remanent magnetization of a PM & $1.43 \mathrm{~T}$ \\
Micro pallet dimensions & $17 \mathrm{~mm} \times 17 \mathrm{~mm} \times 0.5 \mathrm{~mm}$ \\
Glass layer dimensions & $17 \mathrm{~mm} \times 17 \mathrm{~mm} \times 0.13 \mathrm{~mm}$ \\
Weight of the micro pallet & $0.35 \mathrm{grams}$ \\
Fixed part dimensions & $28 \mathrm{~mm} \times 28 \mathrm{~mm} \times 1.4 \mathrm{~mm}$ \\
PEDC thickness (top layer) & $58 \mu \mathrm{m}$ \\
PEDC thickness (second layer) & $33 \mu \mathrm{m}$ \\
Thermal pad & $25 \mathrm{~mm} \times 25 \mathrm{~mm} \times 0.033 \mathrm{~mm}$ \\
Bottom layer copper thickness & $60 \mu \mathrm{m}$ \\
\hline
\end{tabular}

The working principle of the actuator is based on generation of the Lorentz forces. When sinusoidal currents are injected in the respective PEDC to achieve translation motion, a Lorentz force appears due to the interaction between the current in the PEDC and magnetic field generated by the PMs. As a result, the free micro pallet experiences the generated electromagnetic force and moves along the desired direction. In comparison to the previous design proposed by our research team in [14], this new design has been improved in two ways. Firstly, the conductor thickness of the second layer PEDC was increased from $18 \mu \mathrm{m}$ (old design) to $33 \mu \mathrm{m}$ in order to reduce the resistance. As a result, magnitude of the generated joule heat (i.e., $I^{2} R$ ) can be minimized. Secondly, a thermal pad in third layer of the fixed part was integrated [see Fig.1] to disperse generated joule heat. In comparison with the previous design [14], which allows only $0.6 \mathrm{~A}$ current value due to the mentioned design limitations, this new design should solve these issues. Besides, the thermal pad layer together with the thermal vias should improve the temperature evacuation.

Figure 2, represents the microscopic view of the PCB cross section that has been commercially fabricated. All four layers can be easily be identified. From the analysis, the copper thickness of the PEDCs in the top layer and second layer was found to be $58 \mu \mathrm{m}$ and $33 \mu \mathrm{m}$, respectively. Similarly, the thermal pad layer that consists of a $33 \mu \mathrm{m}$ copper layer can be seen. In the bottom layer a $60 \mu \mathrm{m}$, copper layer can be seen which represents the connection traces to deliver the sinusoidal currents in the PEDCs at top and second layer of the fixed part.

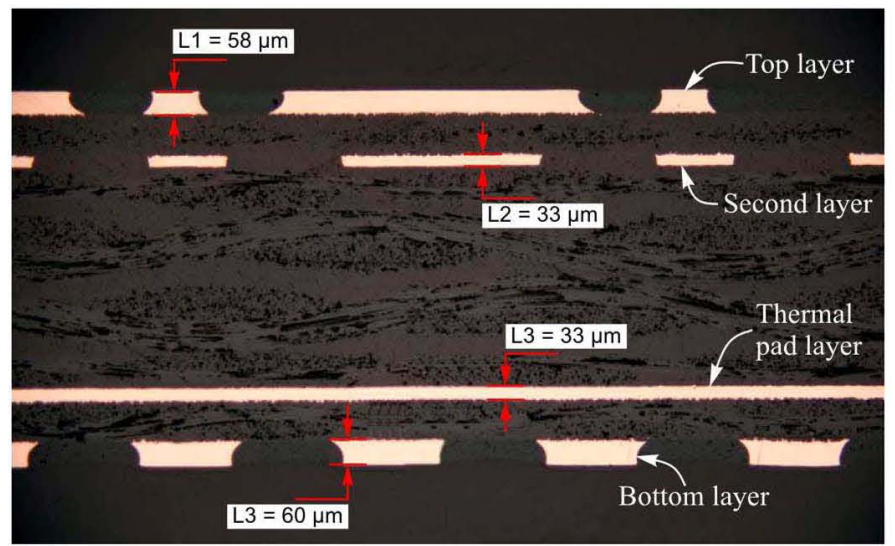

Fig. 2. Microscopic view of the cross section of the fixed part (i.e., PCB) of the multi-layer actuator 


\section{Modeling AND ANAlYSis}

In this section, modeling and analysis has been performed to evaluate the actuator design, especially its thermal behaviour.

\section{A. Electromagnetic force computation model}

The total electromagnetic force (or Lorentz force) applied on the micro pallet has been computed using (1) [13]. This equation takes into account the magnetic flux density due to the PMs and currents in the PEDCs of top and second layer of the fixed part, respectively.

$$
F_{L}=\underbrace{N \sum_{k=1}^{2} I_{k} \int_{\text {wire }} d l \times B_{\text {ext }}^{(k)}}_{\text {for PEDC in top layer }}+\underbrace{N \sum_{q=1}^{2} I_{q} \int_{\text {wire }} d l \times B_{\text {ext }}^{(q)}}_{\text {for PEDC in second layer }}
$$

where, $\mathrm{F}_{L}$ is the total electromagnetic force, $N$ denotes the number of conductors in each PEDC, superscripts $(k)$ and $(q)$ denote the relative position index for magnetic flux density computation with respect to the coils in the PEDCs of top and second layer, respectively. $B_{\text {ext }}$ is the external magnetic flux density components ( $B_{x}$ and $B_{z}$ ) computed using (2) which is based on reduction of $R$ numbers of PMs to equivalent current distribution for computing $B_{x}$ and $B_{z}$ at any point in space due to multiple PMs [15].

$$
\begin{aligned}
B_{x}=\frac{\mu_{0} M_{s}}{4 \pi} & {\left[2 \sum_{i=1}^{R} \ln \left(\frac{(x-2 i w)^{2}+(z-h)^{2}}{(x-2 i w)^{2}+(z+h)^{2}}(-1)^{i}\right)\right.} \\
& -\ln \left(\frac{(x-2 R w)^{2}+(z-h)^{2}}{(x-2 R w)^{2}+(z+h)^{2}}\right) \\
& \left.-\ln \left(\frac{(x+w)^{2}+(z-h)^{2}}{(x+w)^{2}+(z+h)^{2}}\right)\right] \\
B_{z}=\frac{\mu_{0} M_{s}}{2 \pi} & {\left[2 \sum_{i=1}^{R} \operatorname{atan}\left(\frac{2 h(x-2 i w)(-1)^{i}}{(x-2 i w)^{2}+z^{2}-h^{2}}\right)\right.} \\
& -\operatorname{atan}\left(\frac{2 h(x-2 R w)}{(x-2 R w)^{2}+z^{2}-h^{2}}\right) \\
& \left.-\operatorname{atan}\left(\frac{2 h x}{(x-2 w)^{2}+z^{2}-h^{2}}\right)\right]
\end{aligned}
$$

While taking into account the physical characteristics presented in table I, a static analysis in Radia ${ }^{\circledR}$ has been performed to study the generated translation and leviation forces for injected currents ranging from $0.1 \mathrm{~A}$ to $1 \mathrm{~A}$. The objective behind this study was to determine the injected current's amplitude in the top layer PEDC and second layer PEDC, for which an identical translation force can be obtained. From the results presented in Fig. 3, it can be observed that, for a maximum current value of $0.8 \mathrm{~A}$ in second layer PEDC, an identical $9.3 \mathrm{mN}$ translation force can be obtained with $0.6 \mathrm{~A}$ in top layer PEDC. The maximum value of the injected current (i.e., $0.8 \mathrm{~A}$ ) was selected to minimize joule heating due to the small cross section of the conductors in the second layer PEDC. In addition, for the identified current values, i.e., 0.6 A and $0.8 \mathrm{~A}$ in top layer and second layer PEDCs, the levitation force was found to be $10.6 \mathrm{mN}$ and $8.7 \mathrm{mN}$, respectively, as shown in Fig. 3. The difference between the two levitation

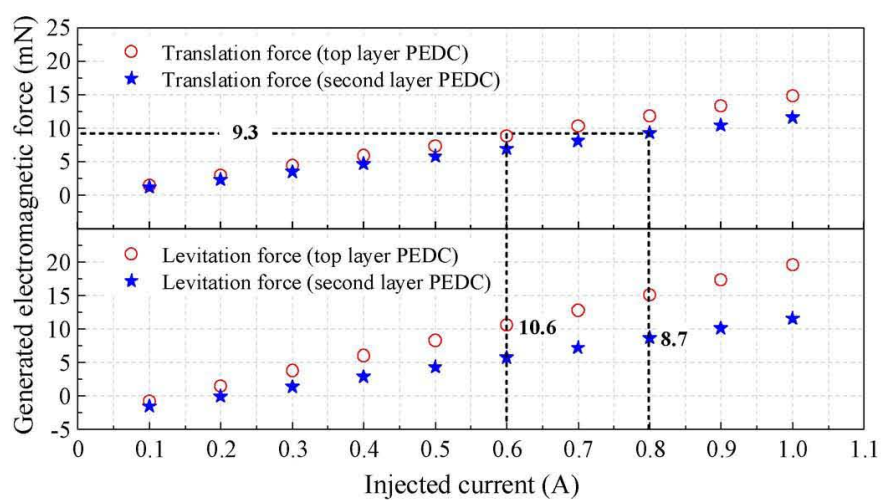

Fig. 3. Static analysis of the generated translation and levitation force with respect to current injected into the PEDCs of top layer and second layer of the fixed part

forces is due to the difference in the air gap between PEDC at top and second layer with respect to PMs.

\section{B. Steady-state thermal analysis of the $P C B$}

In order to study the joule heating effect, a Finite Element Analysis (FEA), to evaluate the maximum temperature rise in the PCB has been performed. The geometrical parameters presented in table I have been incorporated to realize the model in COMSOL ${ }^{\circledR}$ Multiphysics software. However, some simplifications have been adapted to reduce simulation time. At first, the PEDC have been modeled as a linear array of conductors as shown in Fig. 4. Moreover, thermal pad and vias have been modeled as a copper plate (with no currents) in third layer. This choice is made due to the fact that during production of the PCB, the thermal pads have been fabricated as a $33 \mu \mathrm{m}$ thick copper layer [see Fig. 2].

To realize steady state analysis, a $0.8 \mathrm{~A}$ peak current was selected to be injected into both of the PEDCs, i.e., top layer PEDC and second layer PEDC. This choice was made to evaluate the maximum temperature rise in the PCB when both drive coils are used to drive the micro pallet in $x y$ plane. Furthermore, a maximum current of $0.8 \mathrm{~A}$ current was selected by taking into account the geometrical limitation the conductors in the second layer PEDC as discussed in previous subsection. During modeling, general parameters in the $\mathrm{COMSOL}^{\circledR}$ software regarding the material and heat transfer coefficients have been used to simulate the generated joule heat. However, due to the free convection, a commonly used value of $5 \mathrm{~W} / \mathrm{m}^{2}$.C was adopted as convection heat transfer coefficient for the convection in air. For initial condition, a $20^{\circ} \mathrm{C}$ (i.e., $293.15 \mathrm{~K}$ ) was selected as ambient temperature.

From the FEA analysis, it can be observed that the maximum temperature rise at the surface was found to be $57^{\circ} \mathrm{C}$ at the center of the PCB as shown in Fig. 4(a). In the zoom view, the different temperature zones can easily be identified [see Fig. 4(b)]. In the proposed design, the maximum temperature at which PMs start to demagnetize is $150^{\circ} \mathrm{C}$. So, it can be concluded that a $57.13^{\circ} \mathrm{C}$ maximum temperature rise gives a 2.6 times safety factor. In comparison with the earlier design (i.e., without thermal pad) proposed by our research team in [14], the steady state analysis of it revealed a $70^{\circ} \mathrm{C}$ rise in surface temperature for a $0.8 \mathrm{~A}$ current value. Thanks to 



Fig. 4. FEA results for the actuator design with PEDC having copper thickness of $58 \mu \mathrm{m}$ in top layer and $33 \mu \mathrm{m}$ in second layer.

the thermal pad in the third layer of the fixed part of the current electromagnetic actuator design, the maximum rise in temperature has been reduced by a value of $20^{\circ} \mathrm{C}$.

\section{EXPERIMENTATION}

In order to measure the surface temperature of the PCB during functioning of the actuator, an experimental setup has been realized. In order to drive the actuator, the PEDCs at top and second layer has been injected with sinusoidal current generated using a VI convertor (linear conversion, sampling rate of $50 \mathrm{kHz}$, input $[-10 \mathrm{~V},+10 \mathrm{~V}]$, and output [$10 \mathrm{~A},+10 \mathrm{~A}])$ that is controlled with an analog output via the National Instrument ${ }^{\circledR}$ (NI) data acquisition board PCI-6733 [see Fig.4(a)]. The generation of the sinusoidal output current for the actuator has been managed with the help of a Labview software.

In addition, an LM35 temperature sensor was fixed onto the PCB using thermal paste as shown in the Fig.5(b). This sensor was selected due to its direct calibration in centigrade, high temperature measurement range, low cost and small dimensions (see table II for detail characteristics). However, due to the TO-CAN metallic casing of the sensor, it was placed inside a non magnetic through cavity of a cuboid shaped plastic part to ensure a firm contact between the PCB and avoid magnetic interference due to the PMs in the mobile part [see Fig.5(b)]. Moreover, the sensor was installed at the
TABLE II. LM35 SENSOR'S PHYSICAL CHARACTERISTICS

\begin{tabular}{lc}
\hline Parameter & Value \\
\hline Linearity & $+10 \mathrm{mV} /{ }^{\circ} \mathrm{C}$ \\
Accuracy & $0.5^{\circ} \mathrm{C}\left(\right.$ at $\left.25^{\circ} \mathrm{C}\right)$ \\
Measurement range & $-55^{\circ} \mathrm{C}$ to $150^{\circ} \mathrm{C}$ \\
Operting voltage & $4 \mathrm{~V}$ to $30 \mathrm{~V}$ \\
Dimensions (TO-CAN) & $\phi 4.75 \mathrm{~mm} \times 4.9 \mathrm{~mm}$ \\
\hline
\end{tabular}

corner of the fixed part in order to avoid disturbing the micro pallet motion during translation over the fixed part of the actuator. Indeed, there is a temperature difference between the center and corners of the fixed part. However, for initial studies, it was decided to neglect this temperature variation. The output voltage of the sensor was measured using National Instrument ${ }^{\circledR}(\mathrm{NI})$ data acquisition board PCI-6036E. During experimentation, a $5 \mathrm{~ms}$ time delay between each measurement was fixed to acquire stable measured temperature values.


Fig. 5. (a) Block diagram of the experimental setup. (b) Real view

\section{RESUlts AND Discussion}

In this section, the results obtained through different experiments are discussed. The experiments have been initially carried out for a 100 cycles of $8 \mathrm{~mm}$ forward-backward displacement strokes along $\boldsymbol{y}$-axis by injecting sinusoidal currents into the top layer PEDC. For each test, the amplitude of the injected sinusoidal currents was increased from $0.4 \mathrm{~A}$ to $0.8 \mathrm{~A}$ and a maximum surface temperature value was then measured using temperature sensor. In addition, for each current value, 
TABLE III. TOTAL TIME DURATION FOR 100 CYCLES TEST

\begin{tabular}{lcccccc}
\hline Speed $(\mathrm{mm} / \mathrm{s})$ & 1 & 2 & 3 & 4 & 5 & 8 \\
\hline Total time $(\mathrm{s})$ & 800 & 400 & 267 & 200 & 160 & 100 \\
\hline
\end{tabular}

the 100 cycles test was carried out for different motion speed of the mobile part. The total time durations for each test with respect to the motion speed of the micro pallet test are provided in table III .

From Fig 6, it can be seen that the surface temperature of fixed part rises to $14^{\circ} \mathrm{C}$ above room temperature (i.e., $23^{\circ} \mathrm{C}$ ) for a maximum current amplitude value of $0.8 \mathrm{~A}$ at $1 \mathrm{~mm} / \mathrm{s}$ speed. Further, it can be observed that at higher speed such as $8 \mathrm{~mm} / \mathrm{s}$, the temperature rise is very low (i.e., $5^{\circ} \mathrm{C}$ ). This is mainly due to the fact that at higher speed the mobile part tends to finish its desired 100 cycles in less time. Whereas, at lower speeds the mobile part takes more time to finish 100 cycles of $8 \mathrm{~mm}$ displacement stroke (see table III).

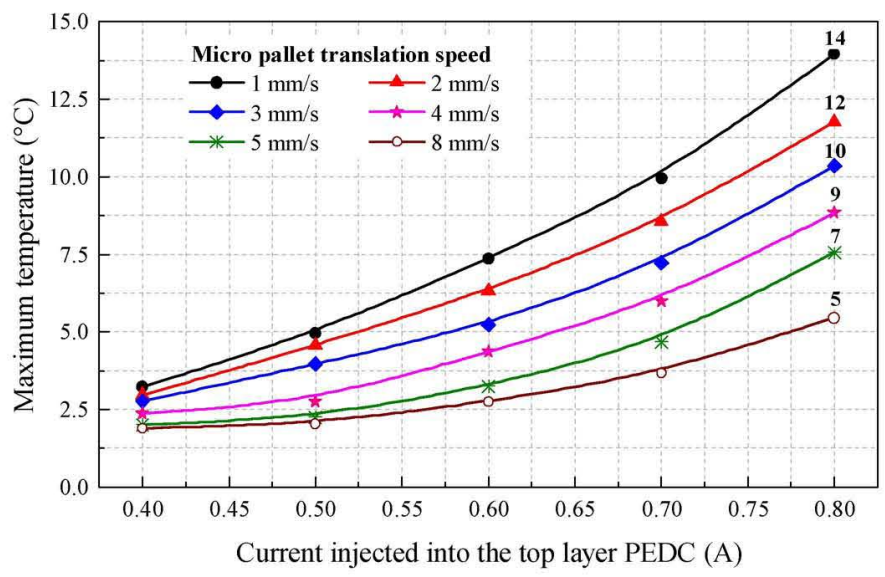

Fig. 6. Maximum temperature rise with respect to different magnitude of injected currents values in the top layer PEDC of the PCB.

After conducting test on top layer PEDC, a 100 cycles displacement test was performed by injecting the identical sinusoidal currents in to the PEDC at second layer to translate the micro pallet up till $8 \mathrm{~mm}$ distance along $x$-axis. The tests were conducted in similar fashion as described earlier. A maximum surface temperature of $30^{\circ} \mathrm{C}$ was measured at $1 \mathrm{~mm} / \mathrm{s}$ speed [see Fig.7]. This rise in temperature is due to the small copper thickness (i.e., $33 \mu \mathrm{m}$ ) of the PEDC in the second layer which lead to higher resistance value. Another reason for the high temperature values is due to the absence of convective cooling of coils at inner layer (i.e., the second layer PEDC), which is sandwiched inside the PCB. Nevertheless, a similar behaviour concerning speed variation can be observed. At higher speed a $10^{\circ} \mathrm{C}$ rise in temperature was measured.

Afterwards, both PEDCs (i.e., top layer and second layer PEDCs) have been injected with $0.8 \mathrm{~A}$ sinusoidal currents to measure the maximum surface temperature. This test was performed to evaluate the scenario where both axes of the actuator are active and the micro pallet moves in $x y$-plane. The injected current parameters were selected as described earlier. For a 100 cycles for $8 \sqrt{2} \mathrm{~mm}$ (i.e., $8 \mathrm{~mm}$ along $x$ and $8 \mathrm{~mm}$ along $y$-axis) displacement stroke in $x y$ direction,

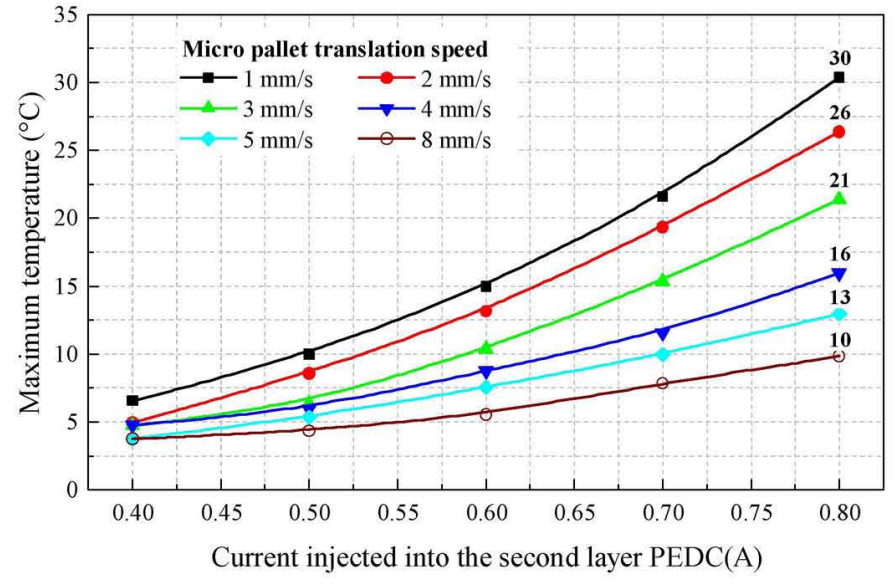

Fig. 7. Maximum temperature rise with respect to different magnitude of injected currents values in the second layer PEDC of the PCB.

a maximum surface temperature of $48^{\circ} \mathrm{C}$ was measured. The high value of the surface temperature is due to the fact that both PEDCs undergoes joule heating. As a result, the total temperature rise is nearly the sum of heat generated by both PEDCs. In comparison to the results obtained via FEA model [see Fig 4], the difference in temperature is due to the fact that the model has been simplified by replacing the thermal vias as copper layer in third layer of the PCB. Furthermore, the FEA results are based on steady state analysis, so at reduced motion speed of the micro pallet, a temperature value near to the one obtained via FEA model could be reached. Nevertheless, similar effect regarding the reduction in the surface temperature relative to motion speed of the micro pallet can be observed in the Fig.8.

In another study, a comparative analysis for a 500 cycles test of $8 \mathrm{~mm}$ displacement stroke was conducted by injecting 0.8 A sinusoidal current into PEDC of top layer, then in second layer and finally in both layers at $2 \mathrm{~mm} / \mathrm{s}$. This test was realized to check the stability and evaluate the temperature rise time and cooling time of the fixed part in these three scenarios. The comparison was carried out for 500 cycles for which the total time of the micro pallet to realize $8 \mathrm{~mm}$ displacement strokes



Fig. 8. Maximum temperature rise with respect to different magnitude of injected currents values in the PEDCs at top layer and second layer of the PCB. 




Fig. 9. Measured surface temperature of the fixed part (i.e., PCB) in a 500 cycles test of $8 \mathrm{~mm}$ displacement test along $x$-axis, $y$-axis, and $x y$-plane of the actuator at $2 \mathrm{~mm} / \mathrm{s}$.

was measured to be 1400 seconds.

Figure 9 shows the comparison between the temperature rise for 500 cycles. It can be observed that the temperature can reach up to $40^{\circ} \mathrm{C}$ when both PEDCs are used simultaneously. In comparison to the FEA results, a difference of $17^{\circ} \mathrm{C}$ could be observed. This difference in results is because of two reasons. Firstly, the motion speed adapted to perform the experiment is $2 \mathrm{~mm} / \mathrm{s}$, so in comparison with results presented in Fig. 8 a difference of $1^{\circ} \mathrm{C}$ can be observed. Secondly, the FEA model provides steady state result, so, it can easily be predicted that at smaller motion speeds (e.g., $0.1 \mathrm{~mm} / \mathrm{s}, 0.05$ $\mathrm{mm} / \mathrm{s}$ ), the surface temperature values can become closer to the one computed through FEA model. Furthermore, from Fig. 9, the variation in cooling time with respect to the $0.8 \mathrm{~A}$ injected sinusoidal current was found to be $250 \mathrm{sec}, 400 \mathrm{sec}, 450 \mathrm{sec}$ for only top layer PEDC, only second layer PEDC, and both layer PEDCs, respectively. The temperature rise and fall time for $10 \%-90 \%$ interval remains less then 200 and 100 seconds, respectively.

\section{CONCLUSION AND FUtURE WORK}

In this paper, a new design of four layers based micro electromagnetic actuator is presented. The thermal behaviour of the design has been evaluated for maximum current handling capability. Through experimentation, it has been observed that, the proposed design can easily carry upto $0.8 \mathrm{~A}$ injected current. The maximum temperature rise of $48^{\circ} \mathrm{C}$ was measured at $1 \mathrm{~mm} / \mathrm{s}$ motion speed of the micro pallet (i.e., the mobile part of the actuator). However, it has been observed that at higher speeds, the actuator tends to generate less heat and the temperature rise remains very low. Further, the PCB is able to handle $0.8 \mathrm{~A}$ sinusoidal currents for a 500 cycles of $8 \mathrm{~mm}$ displacement strokes along both $x$ - and $y$-axis in $x y$-plane.

In future, the actuator design will be further improved and analytical solutions will be developed to perform dynamic simulations. The analytical models based on thermal behaviours will help us to design motion control strategies in this class of actuators. In addition, an in-depth study will be conducted to evaluate numerous physical characteristics (e.g., thermomechanical deformation, variation in resistance, etc.) of the fixed part as well as mobile part of the actuator. Also, different heat evacuation techniques will be studied to further reduce the overall temperature in the fixed part of the actuator.

\section{ACKNOWLEDGMENT}

This work is realized under the MICROCOSM project and supported by the Picardie region and co-financed by Europe/FEDER with the European funds for regional developments at the Picardie region of France.

\section{REFERENCES}

[1] P. Ouyang, R. Tjiptoprodjo, W. Zhang, and G. Yang, "Micro-motion devices technology: The state of arts review," The International Journal of Advanced Manufacturing Technology, vol. 38, no. 5, pp. 463-478, 2008.

[2] M. U. Khan, C. Prelle, F. Lamarque, T. Beutel, and S. Büttgenbach, "Silicon conveyor based planar electromagnetic device for linear displacement," in Advanced Intelligent Mechatronics (AIM), 2010 IEEE/ASME International Conference on, 2010, pp. 231-236.

[3] S. Verma, W. jong Kim, and H. Shakir, "Multi-axis maglev nanopositioner for precision manufacturing and manipulation applications," IEEE Transactions on Industry Applications, vol. 41, no. 5, pp. 1159-1167, Sept 2005.

[4] R. Pelrine, A. Wong-Foy, B. McCoy, D. Holeman, R. Mahoney, G. Myers, J. Herson, and T. Low, "Diamagnetically levitated robots: An approach to massively parallel robotic systems with unusual motion properties," in Robotics and Automation (ICRA), 2012 IEEE International Conference on, 2012, pp. 739-744.

[5] X. Lu and I. u. r. Usman, "6D direct-drive technology for planar motion stages," CIRP Annals - Manufacturing Technology, vol. 61, no. 1, pp. 359-362, 2012.

[6] M. U. Khan, N. Bencheikh, C. Prelle, F. Lamarque, T. Beutel, and S. Büttgenbach, "A long stroke electromagnetic $X Y$ positioning stage for micro applications," Mechatronics, IEEE/ASME Transactions on, vol. 17, no. 5, pp. 866-875, 2012.

[7] S. Xiao and Y. Li, "Optimal design, fabrication, and control of an $x y$ micropositioning stage driven by electromagnetic actuators," Industrial Electronics, IEEE Transactions on, vol. 60, no. 10, pp. 4613-4626, 2013.

[8] K. H. Kim, H. J. Yoon, O. C. Jeong, and S. S. Yang, "Fabrication and test of a micro electromagnetic actuator," Sensor and Actuators A, vol. 117, pp. 8-16, 2005.

[9] D. L. Roy, G. Shaw, R. Haettel, K. Hasselbach, F. Dumas-Bouchiat, D. Givord, and N. M. Dempsey, "Fabrication and characterization of polymer membranes with integrated arrays of high performance micromagnets," Materials Today Communications, vol. 6, pp. 50 - 55, 2016.

[10] B. Ma, A. Sun, Z. Lu, C. Cheng, and C. Xu, "Research on anisotropic bonded $\mathrm{Nd}-\mathrm{Fe}-\mathrm{B}$ magnets by 2 -step compaction process," Journal of Magnetism and Magnetic Materials, vol. 401, pp. 802 - 805, 2016.

[11] V. H. Nguyen and W. jong Kim, "Novel electromagnetic design for a precision planar positioner moving over a superimposed concentratedfield magnet matrix," Energy Conversion, IEEE Transactions on, vol. 27, no. 1, pp. 52-62, 2012.

[12] J. W. Jansen, C. M. M. van Lierop, E. A. Lomonova, and A. J. A. Vandenput, "Modeling of magnetically levitated planar actuators with moving magnets," IEEE Transactions on Magnetics, vol. 43, no. 1, pp. 15-25, Jan 2007.

[13] M. U. Khan, C. Prelle, F. Lamarque, and S. Buttgenbach, "Dual drive coils design for a long stroke electromagnetically actuated micropositioning system," in Advanced Intelligent Mechatronics (AIM), 2015 IEEE International Conference on, July 2015, pp. 842-847.

[14] N. Arora, M. U. Khan, L. Petit, and C. Prelle, "A planar electromagnetic actuator based on two layer coil assembly for micro applications," in 014 IEEE/ASME International Conference on Advanced Intelligent Mechatronics (AIM) Besançon, France,, July 8-11 2014, pp. 174-179.

[15] E. P. Furlani, Permanent Magnet and Electromechanical DevicesMaterials, Analysis and Applications. San Diego, CA: Academic, 2001. 